\title{
The Use of Complementary and Alternative Medicine Among Cancer Patients Treated with Radiotherapy
}

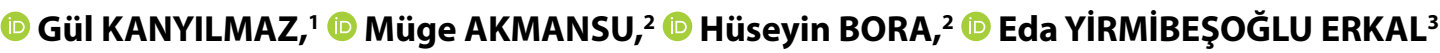 \\ 'Department of Radiation Oncology, Necmettin Erbakan University, Meram Faculty of Medicine, Konya-Turkey \\ ${ }^{2}$ Department of Radiation Oncology, Gazi University Faculty of Medicine, Ankara-Turkey \\ ${ }^{3}$ Department of Radiation Oncology, Kocaeli University Faculty of Medicine, Kocaeli-Turkey
}

\begin{abstract}
OBJECTIVE
The purpose of this study was to determine: (1) the prevalence of complementary and alternative medicine (CAM) use (2) the characteristics of CAM users, (3) patients' source of information about CAM, (4) patients' perceived attitude of their physician regarding CAM use, and (5) the association between CAM use and Hospital Anxiety and Depression Scale (HADS).
\end{abstract}

\section{METHODS}

This descriptive-cross section study was conducted between June 2007 and December 2007. Three-hundred and six patients were asked to complete a questionnaire about the use of CAM along with HADS.

\section{RESULTS}

The prevalence of CAM use among cancer patients treated with radiotherapy was $35 \%$. The patients with severe anxiety score were more likely to use CAM than the others. The younger age were found as predicting variables for CAM use. Majority of user patients wanted to add CAM to conventional therapies.

\section{CONCLUSION}

Oncologist might be aware of the CAM issue and talk to their patients about the use of CAM. The documentation of CAM use in the medical history might be advised at the time of initial consultation in radiotherapy centers. Although CAM use is a method that patients want to use in addition to conventional treatments, it is not clear that these methods can be used together safely. It is thought that there is a need for prospective and innovative studies in modern oncology centers.

Keywords: Alternative medicine, cancer; complementary medicine; hospital anxiety and depression score; radiotherapy. Copyright $\odot$ 2022, Turkish Society for Radiation Oncology

\section{Introduction}

The prevalence of complementary and alternative medicine $(\mathrm{CAM})$ use in cancer patients varies between $30 \%$ and $90 \%$.[1] The use of CAM depends on the patient's culture, religion, and geographical location.[2] In Europe, approximately $15-75 \%$ of adults use CAM whereas, in the United States, CAM use rate is around $40 \% \cdot[2,3]$ Most of the studies about CAM use in cancer patients come from developed countries, with only a few data from developing countries. The prevalence of CAM use in Turkey has been reported to range between $36 \%$ and $81 \%$.[4-9] The prevalence of CAM use in Turkish cancer patients treated with radiotherapy is not clear.

The management of treatment-related side effects is an important goal in oncology and the use of CAM may be a pillar in this situation. The safety and efficacy for 
the use of CAM along with conventional therapies have not been established and certain CAM therapies might lead to excessive toxicity when used concurrently with chemotherapy or radiotherapy.[10] Furthermore, only one-quarter of cancer patients give information from their health care managers about using CAM.[6-9,11] Therefore, it is important to gain evidence-based information about CAM use when a more holistic approach is considered.[12]

Coping with cancer and its treatment has profound implications on individuals. Studies have demonstrated that approximately one-third of cancer patients deal with clinically significant anxiety and depression. $[13,14]$ In the oncology setting, Hospital Anxiety and Depression Scale (HADS) is one of the most commonly used self-assessment tools for evaluating anxiety and depression. Several studies have shown that CAM is an effective intervention for cancer patients in reducing emotional distress and improving quality of life and general well-being. [15,16]

Few studies have evaluated the association between CAM use and HADS scores in cancer patients. Rakovitch et al.[17] have reported on the lack of association between HADS scores and CAM use in patients with breast cancer. However, Hyodo et al.[18] have reported low HADS anxiety scores and high HADS depression scores to be correlated with CAM use in cancer patients. The association between CAM use and HADS scores regarding Turkish cancer patients treated with radiotherapy is relatively unknown.

The purpose of this study was to determine: (1) the prevalence of CAM use among Turkish cancer patients treated with radiotherapy, (2) the characteristics of CAM users, (3) patients' source of information about CAM, (4) patients' perceived attitude of their physician regarding CAM use, and (5) the association between CAM use and HADS scores.

\section{Materials and Methods}

\section{Research Setting and Sample}

This descriptive cross-sectional study was conducted from June to December 2007 at the Radiotherapy Department of one University Medical School.

\section{The Questionnaire}

We used a standardized newly developed interviewer-administered questionnaire. The questionnaire was intended to collect information about socio-demographic characteristics (e.g., age, income level, educa- tion status, employment status), disease (e.g., breast, lung, head, and neck cancer) and treatment characteristics of patients (e.g., radiotherapy, chemotherapy, surgery) and use of CAM status (e.g., use of CAM, reasons for CAM use, type(s) of CAM used, beliefs the benefit of CAM). Patients were questioned if they had discussed the use of CAM with their oncologist. Patients were also asked to describe the perceptions among physicians about their CAM use and about the reasons for not discussing CAM with their physicians.

We also assessed the levels of anxiety and depression using the HADS.[19] HADS is a self-rated 14-item questionnaire, was developed to determine states of anxiety, depression, and emotional status of patients. Seven questions in the HAD deal with anxiety and seven with depression (HADS-A and HADS-D). The answers to every question are scored on a scale of $0--3$. The highest score of point is thus 21. Amount higher than 10 are accepted to indicate probable severe case.

\section{Data Collection}

All patients were informed and written consent was obtained by a face-to-face interview. In total, $306 \mathrm{pa}$ tients completed the questionnaire regarding the use of CAM along with the HADS.

\section{Ethical Considerations}

The study design was approved by the administrators of the Department of Radiation Oncology. Ethical approval was obtained from the Ethical Review Committee of Gazi University Medicine School.

\section{Statistical Analysis}

Statistical analysis was carried out using Statistical Package for Social Sciences for Windows version 13 (SPSS. Inc. Chicago. IL). Categorical variables were compared using Pearson's Chi-square test and continuous variables were compared using independent samples t-test and ANOVA test. The correlations were evaluated using Spearman's rho correlations. For all statistical analysis, a two-sided $\mathrm{p}<0.05$ was considered to be statistically significant.

\section{Results}

Patient characteristics are presented in Table 1 and reasons for CAM use are presented in Table 2.

Among 107 patients who were CAM users (the vast majority using herbal medicine), CAM use was based on their personal experiences in 13 (12.1\%), the expe- 
riences or suggestions of their family members in 62 (57.9\%), the experiences or suggestions of other fellow patients in $36(33.6 \%)$, the recommendations of their physicians in 17 (15.9\%) and the experiences or suggestions shared on the media in 43 (40\%). Only 46 out of 107 patients (43\%) had discussed their CAM use with their attending physicians.

Of 34 patients with HADS-A scores $\geq 11,22$ patients (65\%) experienced severe anxiety whereas of 60 patients with HADS-D scores $\geq 11,22$ patients (37\%) experienced severe depression. There was a statistically significant correlation between higher HADS-A scores and higher HADS-D scores $(\mathrm{p}<0.001, \mathrm{r}=0.642)$.

Of 34 patients experiencing severe anxiety, there were 27 females (79.4\%) and seven males (20.6\%), their ages ranging from 26 to 77 years (median, 53 years). Nine patients (26.5\%) had completed high school education or more. Twenty-six of them (76.5\%) lived in

\section{Table 1 Patient characteristics}

\begin{tabular}{|c|c|c|c|c|}
\hline Characteristics & $\begin{array}{c}\text { All } \\
(n=306)\end{array}$ & $\begin{array}{l}\text { CAM (+) } \\
(n=107)\end{array}$ & $\begin{array}{l}\text { CAM (-) } \\
(n=199)\end{array}$ & $\mathbf{p}$ \\
\hline \multicolumn{5}{|l|}{ Age (years) } \\
\hline Median (Range) & $53(16-81)$ & $52(16-77)$ & $53(16-81)$ & 0.25 \\
\hline \multicolumn{5}{|l|}{ Gender, n (\%) } \\
\hline Male & $143(47)$ & $48(45)$ & $95(48)$ & 0.7 \\
\hline Female & $163(53)$ & $59(55)$ & $104(52)$ & \\
\hline \multicolumn{5}{|l|}{ Educational level, n (\%) } \\
\hline Illitarate/Primary & $165(54)$ & $58(54)$ & $107(54)$ & 0.9 \\
\hline Secondary & $89(29)$ & $30(28)$ & $59(29)$ & \\
\hline University & $52(17)$ & $19(18)$ & $33(17)$ & \\
\hline \multicolumn{5}{|l|}{ Marital status, n (\%) } \\
\hline Single & $24(86)$ & $8(6)$ & $16(8)$ & 0.9 \\
\hline Married & $263(8)$ & $92(86)$ & $171(86)$ & \\
\hline Divorced or widowed & $19(6)$ & $7(6)$ & $12(6)$ & \\
\hline \multicolumn{5}{|l|}{ Job status, n (\%) } \\
\hline Jobless & $131(43)$ & $51(48)$ & $80(40)$ & 0.2 \\
\hline Working & $175(57)$ & $56(52)$ & $119(60)$ & \\
\hline Income (Turkish Lira) & $1179 \pm 967.7$ & $1235 \pm 898.4$ & $1149 \pm 1003$ & 0.4 \\
\hline Number of children median, (range) & $3(0-10)$ & $3(0-10)$ & $3(0-8)$ & 0.5 \\
\hline Cancer type, n (\%) & & & & $0.015^{*}$ \\
\hline Breast & $90(26)$ & $38(42)$ & $52(58)$ & 0.08 \\
\hline Lung & $41(10)$ & $21(51)$ & $20(49)$ & $0.019 *$ \\
\hline Prostate & $15(5)$ & $6(40)$ & $9(60)$ & 0.7 \\
\hline Brain & $29(12)$ & $6(21)$ & $23(79)$ & 0.09 \\
\hline Head and neck & $47(18)$ & $11(23)$ & $36(77)$ & 0.07 \\
\hline Gastrointestinal & $45(17)$ & $10(22)$ & $35(78)$ & 0.05 \\
\hline Others & $39(12)$ & $15(39)$ & $24(61)$ & 0.6 \\
\hline \multicolumn{5}{|l|}{ Treatment, n (\%) } \\
\hline Radiotherapy & $18(6)$ & $4(4)$ & $14(7)$ & 0.24 \\
\hline Chemoradiotherapy & $288(94)$ & $103(96)$ & $185(93)$ & \\
\hline HADS-A, n (\%) & & & & 0.06 \\
\hline 0-7 (normal) & $229(75)$ & $76(71)$ & $153(77)$ & 0.2 \\
\hline 8-10 (borderline) & $43(14)$ & $13(12)$ & $30(15)$ & 0.4 \\
\hline 11-21 (severe) & $34(11)$ & $18(17)$ & $16(8)$ & $0.02^{*}$ \\
\hline HADS-D, n (\%) & & & & 0.8 \\
\hline 0-7 (normal) & $209(68)$ & $75(70)$ & $134(67)$ & 0.6 \\
\hline 8-10 (borderline) & $37(12)$ & $12(11)$ & $25(13)$ & 0.7 \\
\hline 11-21 (severe) & $60(20)$ & $20(19)$ & $40(20)$ & 0.7 \\
\hline
\end{tabular}

*Statistically significant. CAM: Complementary and alternative medicine; HADS-A: Hospital anxiety and depression scale-anxiety; HADS-D: Hospital anxiety and depression scale-depression 
Table 2 Patients' believes regarding the effectiveness of CAM use ( $n=107)$

\begin{tabular}{|c|c|c|c|c|}
\hline \multirow[t]{2}{*}{ Reasons for CAM use } & \multicolumn{2}{|c|}{ No } & \multicolumn{2}{|c|}{ Yes } \\
\hline & $\mathbf{n}$ & $\%$ & $\mathbf{n}$ & $\%$ \\
\hline Believe that CAM will improve the effect of therapy & 53 & 49.5 & 54 & 50.5 \\
\hline Prevent side effects of therapy & 100 & 93.5 & 7 & 6.5 \\
\hline Feel better emotionally & 87 & 81 & 20 & 19 \\
\hline
\end{tabular}

CAM: Complementary and alternative medicine

cities. Twenty-two patients (64.7\%) had ECOG performance scores of 0 or 1 . Thirteen patients $(38.2 \%)$ were employed. Thirty-one patients (91.2\%) were married, sixteen patients $(47.1 \%)$ were with children and thirtytwo of them $(94.1 \%)$ lived in a family-hood. Twentytwo patients (64.7\%) were also experiencing severe depression. Eighteen of them (52.9\%) were using CAM and 14 of them (41.2\%) had discussed CAM use with their physicians (Table 3 ).

Of 272 patients experiencing no anxiety, there were 136 females (50\%), their ages ranging from 16 to 81 years (median, 53 years). 97 patients (35.7\%) had completed high school education or more. 179 of them $(65.8 \%)$ lived in cities. 237 patients (87.1\%) had ECOG performance scores of 0 or 1.162 patients (59.6\%) were employed. 232 patients (85.3\%) were married, 142 patients (52.2\%) were with children and 257 of them (94.5\%) lived in a family-hood. Thirty-eight patients (14\%) were experiencing severe depression. Ninety-four patients (34.6\%) had discussed CAM use with their physicians and 89 of them (32.7\%) were using CAM (Table 3 ).

Female patients $\left(\mathrm{p}=0.02, \chi^{2}=10.70\right)$, patients with worse ECOG scores $\left(\mathrm{p}=0.002, \chi^{2}=11.69\right)$ and patients that were unemployed $\left(\mathrm{p}=0.03, \chi^{2}=5.61\right)$ tended to experience severe anxiety more commonly.

Of 60 patients experiencing severe depression, there were 42 females (70\%) and 18 males (30\%), their ages ranging from 17 to 78 years (median, 53.5 years). Twenty patients (33.3\%) had completed high school education or more. Forty of them (68.3\%) lived in cities. Forty-four patients (73.3\%) had ECOG performance scores of 0 or 1.27 patients (45\%) were employed. Fifty-two patients $(86.7 \%)$ were married, 30 patients (50\%) were with children and 55 of them $(91.7 \%)$ lived in a family-hood. Twenty-two patients $(36.7 \%)$ were also experiencing severe anxiety. Twenty-four patients (40\%) had discussed CAM use with their physicians and 20 of them (33.3\%) were using CAM (Table 4).

Of 46 patients experiencing no depression, there were 122 females (49.6\%) and 124 males (50.4\%), their ages ranging from 16 to 81 years (median, 53 years). 86 patients (35\%) had completed high school education or more. One hundred and sixty-four of them (66.7\%) lived in cities. Two hundred and fifteen patients $(87.4 \%)$ had ECOG performance scores of 0 or 1 . One hundred and forty-eight patients $(60.2 \%)$ were employed. Two hundred and eleven patients (85.8\%) were married, 128 patients (52\%) were with children and 235 of them $(95.5 \%)$ lived in a family-hood. Twelve patients (4.9\%) were experiencing severe anxiety. Eighty-seven of them (35.4\%) were using CAM and 84 of them $(34.1 \%)$ had discussed CAM use with their physicians (Table 4).

Female patients $\left(p=0.004, \chi^{2}=8.39\right)$, patients with worse ECOG scores $\left(\mathrm{p}=0.01, \chi^{2}=7.34\right)$ and patients that were unemployed ( $\left.\mathrm{p}=0.04, \chi^{2}=4.53\right)$ tended to experience severe depression more commonly.

There was a statistically significant difference between patients that used CAM and that did not use CAM concerning rates of those experiencing severe anxiety $\left(\mathrm{p}=0.02, \chi^{2}=5.43\right)$. On the other hand, there was no statistically significant difference between patients that used CAM and that did not use CAM concerning rates of those experiencing severe depression $\left(\mathrm{p}=0.77, \chi^{2}=0.09\right)$.

\section{Discussion}

In this study, we found that the prevalence of CAM use among cancer patients undergoing radiotherapy was $35 \%$. Moreover, $33 \%$ of the patients were planning to use CAM following conventional cancer treatment. This rate was in accordance with those reported in similar surveys. A systematic review of 26 studies from 13 countries showed that the overall rate of CAM use among cancer patients was 31\% (range, 7-64\%). [20] Similarly, in a study investigating CAM use in 14 European countries including Turkey, the overall rate of CAM use was reported as 36\% (range, 15-73\%).[21]

Some studies suggest that CAM use is more common in patients who are younger, who are married, 
Table 3 Patients characteristics according to anxiety status

\begin{tabular}{|c|c|c|c|c|}
\hline Characteristics & $\begin{array}{c}\text { All } \\
(n=306)\end{array}$ & $\begin{array}{l}\text { Severe anxiety } \\
\qquad(n=34)\end{array}$ & $\begin{array}{l}\text { The others } \\
(n=272)\end{array}$ & $\mathbf{p}$ \\
\hline \multicolumn{5}{|l|}{ Age (years) } \\
\hline Median (range) & $53(16-81)$ & $53(26-77)$ & $53(16-81)$ & 0.8 \\
\hline \multicolumn{5}{|l|}{ Gender, n (\%) } \\
\hline Male & $143(47)$ & 7 (20.6) & $136(50)$ & $0.02^{*}$ \\
\hline Female & $163(53)$ & $27(79.4)$ & $136(50)$ & \\
\hline \multicolumn{5}{|l|}{ Educational level, n (\%) } \\
\hline Illitarate/primary & $200(65.4)$ & $25(73.5)$ & $175(35.6)$ & 0.3 \\
\hline Secondary/university & $106(34.6)$ & $9(26.5)$ & $97(64.4)$ & \\
\hline \multicolumn{5}{|l|}{ Place of residence, $\mathrm{n}(\%)$} \\
\hline City & $205(67)$ & $26(76.5)$ & $179(65.8)$ & 0.4 \\
\hline The others & $101(33)$ & $8(23.5)$ & $93(34.2)$ & \\
\hline \multicolumn{5}{|l|}{ ECOG score } \\
\hline 0-1 & $259(84.6)$ & $22(64.7)$ & $237(87.1)$ & $0.002^{*}$ \\
\hline$\geq 2$ & $47(15.4)$ & $12(35.3)$ & 35 (12.9) & \\
\hline \multicolumn{5}{|l|}{ Job status, n (\%) } \\
\hline Jobless & $131(43)$ & $21(61.8)$ & $110(40.4)$ & $0.03^{*}$ \\
\hline Working & $175(57)$ & $13(38.2)$ & $162(59.6)$ & \\
\hline \multicolumn{5}{|l|}{ Marital status, n (\%) } \\
\hline Single & $24(86)$ & $2(5.9)$ & $22(8.1)$ & 0.6 \\
\hline Married & $263(8)$ & $31(91.2)$ & $232(85.3)$ & \\
\hline Divorced or widowed & $19(6)$ & $1(2.9)$ & $18(6.6)$ & \\
\hline \multicolumn{5}{|l|}{ Having children, n (\%) } \\
\hline Yes & $158(51.6)$ & $16(47.1)$ & $142(52.2)$ & 0.5 \\
\hline No & $148(48.4)$ & $18(52.9)$ & $130(47.8)$ & \\
\hline \multicolumn{5}{|l|}{ Severe depression } \\
\hline Yes & $60(20)$ & $22(64.7)$ & $38(14)$ & $<0.0001^{*}$ \\
\hline No & $246(80)$ & $12(35.3)$ & $234(86)$ & \\
\hline \multicolumn{5}{|l|}{ CAM use } \\
\hline Yes & $107(35)$ & $18(52.9)$ & $89(32.7)$ & $0.02 *$ \\
\hline No & $199(65)$ & $16(47.1)$ & $183(67.3)$ & \\
\hline \multicolumn{5}{|c|}{ Discussed CAM use with their physician } \\
\hline Yes & $108(35.3)$ & $14(41.2)$ & $94(34.6)$ & 0.4 \\
\hline No & $198(64.7)$ & $20(58.8)$ & $178(65.4)$ & \\
\hline
\end{tabular}

*Statistically significant. CAM: Complementary and alternative medicine

who have higher income, who have higher education, and who hold health insurance.[2,5,22] In our study, CAM users did not differ from non-users in terms of income, educational status, marital status, and health insurance.

Although CAM use was higher in patients with longer survival,[9] our study showed that lung cancer patients (with expectedly shorter survival) were more likely to use CAM as compared to others. Lung cancer patients might be more inclined toward CAM use due to their seemingly poorer prognosis and the associated rapid physical decline. Kristoffersen et al.[23] have also reported CAM use to be higher among patients with poorer prognosis.
The main reasons for Turkish cancer patients to use CAM were similar to reports from other countries. $[6,7,9,21]$ In our study, $33 \%$ of patients used CAM based on information gathered from other patients who had benefited from such treatment. The vast majority of patients were using herbal medicine. Almost half of the CAM users expected CAM to cure their disease on its own, while $19 \%$ of patients used CAM to improve their emotional and physical well-being and $7 \%$ of patients used it to improve their quality of life through relieving various symptoms caused either by cancer or its conventional treatment. According to our study, 25\% of CAM users seemed to be satisfied with their CAM 
Table 4 Patients characteristics according to depression status

\begin{tabular}{|c|c|c|c|c|}
\hline Characteristics & $\begin{array}{c}\text { All } \\
(n=306)\end{array}$ & $\begin{array}{l}\text { Severe depression } \\
\qquad(n=60)\end{array}$ & $\begin{array}{l}\text { The others } \\
(n=246)\end{array}$ & $\mathbf{p}$ \\
\hline \multicolumn{5}{|l|}{ Age (years) } \\
\hline Median (Range) & $53(16-81)$ & $53.5(17-78)$ & $53(16-81)$ & 0.4 \\
\hline \multicolumn{5}{|l|}{ Gender, n (\%) } \\
\hline Male & $143(47)$ & $18(30)$ & $125(50.8)$ & $0.004^{*}$ \\
\hline Female & $163(53)$ & $42(70)$ & $121(49.2)$ & \\
\hline \multicolumn{5}{|l|}{ Educational level, n (\%) } \\
\hline Illitarate/Primary & $200(65.4)$ & $40(66.7)$ & $160(65)$ & 0.8 \\
\hline Secondary/University & $106(34.6)$ & $20(33.3)$ & $86(35)$ & \\
\hline \multicolumn{5}{|l|}{ Place of residence, $\mathrm{n}(\%)$} \\
\hline City & $205(67)$ & $41(68.3)$ & $164(66.7)$ & 0.3 \\
\hline The others & $101(33)$ & $19(31.7)$ & $82(33.3)$ & \\
\hline \multicolumn{5}{|l|}{ ECOG score } \\
\hline $0-1$ & $259(84.6)$ & $44(73.3)$ & $215(87.4)$ & $0.01 *$ \\
\hline$\geq 2$ & $47(15.4)$ & $16(26.7)$ & $31(12.6)$ & \\
\hline \multicolumn{5}{|l|}{ Job status, n (\%) } \\
\hline Jobless & $131(43)$ & $33(65)$ & $98(39.8)$ & $0.04^{*}$ \\
\hline Working & $175(57)$ & $27(45)$ & $148(60.2)$ & \\
\hline \multicolumn{5}{|l|}{ Marital status, n (\%) } \\
\hline Single & $24(86)$ & $5(8.3)$ & $19(7.7)$ & \\
\hline Married & $263(8)$ & $52(86.7)$ & $211(85.8)$ & 0.9 \\
\hline Divorced or widowed & $19(6)$ & $3(5)$ & $16(6.5)$ & \\
\hline \multicolumn{5}{|l|}{ Having children, n (\%) } \\
\hline Yes & $158(51.6)$ & $30(50)$ & $128(52)$ & 0.8 \\
\hline No & $148(48.4)$ & $30(50)$ & $118(48)$ & \\
\hline \multicolumn{5}{|l|}{ Severe anxiety } \\
\hline Yes & $34(11.1)$ & $22(36.7)$ & $12(4.9)$ & $<0.0001^{*}$ \\
\hline No & $272(88.9)$ & $38(63.3)$ & $234(95.1)$ & \\
\hline \multicolumn{5}{|l|}{ CAM use } \\
\hline Yes & $107(35)$ & $20(33.3)$ & $87(35.4)$ & 0.8 \\
\hline No & $199(65)$ & $40(46.7)$ & $159(64.6)$ & \\
\hline \multicolumn{5}{|c|}{ Discussed CAM use with their physician } \\
\hline Yes & $108(35.3)$ & $24(40)$ & $84(34.1)$ & 0.4 \\
\hline No & $198(64.7)$ & $36(60)$ & $162(65.9)$ & \\
\hline
\end{tabular}

*Statistically significant. CAM: Complementary and alternative medicine

use and $23 \%$ revealed that they would advice others to use CAM. Although half of CAM users wanted to use CAM in addition to their conventional cancer therapies, there is yet no evidence for safety and efficacy regarding the use of CAM in such manner.[24-28]

One of the limitations of the present study is the unintentional focusing of the questionnaire on the use of "phytotherapy" rather than covering a broader spectrum of complementary and alternative medical approaches. This may have resulted in the participants to report their use of herbal medicine and, perhaps, not to appreciate the importance of the use of other modalities in the context of the study. There- fore, a follow-up study that includes a broader set of questions may help to better understand the attitudes of the patients regarding CAM. Surprisingly, the oncologists that are surveyed on CAM use are generally enthusiastic and supportive of their patients' use of complementary therapies. In addition to those therapies popular among patients, at least half of the physicians supported massages, support groups, acupuncture, and biofeedback, and art therapy. However, discussions of CAM are relatively rare and most likely to be initiated by patients. [29] The American Cancer Society urges patients who are thinking about using any CAM types to disclose this with their health care 
managers. [30] The decision to use CAM without informing the attending physicians might lead to a lack of direct communication and informed dialogs in the patient physician relationship, leading patients to base their decisions on informal sources such as other patients, family members, or the Internet.[29] However, only one-quarter of cancer patients provide information for their health care managers on the use of CAM. $[6-9,11]$ It is probable that patients do not discuss CAM use with their health care managers based on the fear of negative feedback. For physicians, good communication skills and open discussion about CAM use is the key to protect patients from unsuitable and unhelpful CAM use while assisting them to obtain the best decision regarding CAM use. In a recent study, although the use of CAM during RT was considered to be quite low when compared to similar studies, the majority of patients that did use CAM would not discuss this with their attending physicians and complained about not having enough information concerning CAM use. The authors concluded that most of the patients were not personally offered to use CAM by their attending physicians, stressing the idea that CAM should be offered on a professional basis in larger cancer centers.[31]

Patients may have different needs to use CAM and may have different perceptions on the risks of interaction between CAM and radiation therapy, as the latter is "not a medication." It is important that physicians and other health care personnel involved in taking care of cancer patients be aware of these therapies, their prevalence, and their beneficial and adverse effects. Adequate knowledge and training of CAM in the medical community would promote a better physicianpatient relationship and foster a more open discussion on their use.

Future research needs to assess effective ways for oncologists to gather information about CAM use by patients during allopathic treatment and discern ways these therapies may enhance or interfere with traditional cancer treatments. Aiming to integrate traditional and complementary medicine practices to modern medical practices, hence improving the quality of life of the society, Turkish Ministry of Health has established The Department of Traditional and Complementary Medicine Practices in 2011. The Department has so far published the rules and regulations in order to certify, license, legislate and organize traditional and complementary medicine practices. There are many differences in terms of the reasons to use traditional or complementary practices on a country basis or on a regional basis, such as the increase in the demand for health services, being more informed about and involved in treatment, being more aware of the available choices, the increase in the dissatisfaction with the available health services and living up of the interest in integrated healthcare and prevention of diseases. An increase in the safe and effective use of CAM could improve these services' access to the healthcare system with the possibilities for integration of these two (http://tcamanatolia.saglik.gov.tr.).[32]

Multiple studies show a willingness on the part of physicians to get more educated about CAM use. Many universities offer increasing number of courses for physicians to enrich their knowledge about CAM therapies and improve the therapeutic encounters with their patients.[33] Patients are increasingly referred to CAM practitioners by some primary care physicians. [34] However, studies are lacking to document if such a trend has extended to patient population. It may be important for physicians in the field of radiation oncology to gain similar expertise. In the absence of controlled clinical trials relating to the safety and efficacy on the use of dietary supplements while on radiation therapy for cancer, it is important not just for patients but also for physicians to be knowledgeable about CAM use and to be diligent in acquiring this vital information from their patients. With the increasing access to information in this population, CAM use will continue to grow and patients will continue using this for a variety of reasons. Their use may have some unexplained benefits among users and the current dictum of restricting therapy to just those medications approved by the FDA needs to be reconsidered. Physicians need to educate themselves and be prepared to have meaningful discussions with patients regarding potential benefits and adverse effects.

The literature suggests that CAM use was associated with anxiety, depression, and poor mental health. [35] In our study, female patients, patients with worse ECOG scores, and patients that were unemployed tended to experience severe anxiety more commonly. Those patients experiencing higher levels of anxiety tended to use CAM more frequently, whereas there was no difference in terms of CAM use based on their state of depression. The studies evaluating the relation between HADS scores and CAM use have reported contradictory results.[14,35,36] Rakovitch et al.[17] did not found any association between high HADS score and CAM use, whereas the other studies showed the correlation between higher level of anxiety or depression score and CAM use.[35,36] 


\section{Conclusion}

Since one-third of the patients in the present study are users of CAM and another one-third of the patients are actively considering the possibility of CAM use, the oncology team should be better prepared to discuss the potential advantages as well as the disadvantages to be observed when using CAM. Furthermore, anxiety and depression, that appear to be common co-existing problems in cancer patients undergoing intensive treatments, should be addressed as necessary in a multidisciplinary context with the help of psychiatrists, clinical psychologists, and social workers.

Better communication, detailed information, and open discussion with the patients is very important for the protection of patients from unsuitable and unhelpful use of CAM. Oncologists might be advised to be aware of the CAM issue and talk to their patients about the use of CAM in their routine practice. The documentation of CAM use in the medical history might be advised at the time of initial consultation in radiotherapy centers.

The use of validated screening tools specific to CAM therapies would assist healthcare professionals to advise patients on continuing their CAM use in light of current literature. In the first instance, healthcare professionals should recommend patients cease CAM therapies with a known risk of harm. Further research is needed to identify how a health professional can encourage and incorporate CAM therapies safely into a treatment regimen. Prospective trials and innovative evidence-based treatment concepts to include CAM into high-end oncology is what patients demand and what a modern oncology center should consider offering.

\section{Peer-review: Externally peer-reviewed.}

Conflict of Interest: All authors declared no conflict of interest.

Ethics Committee Approval: The study was approved by the Gazi University Faculty of Medicine Ethical Review Committee at 2007.

Financial Support: This study has received no financial support.

Authorship contributions: Concept - E.E.Y., G.K.; Design - E.Y.E., G.K.; Supervision - H.B., G.K., M.A.; Funding G.K., E.Y.E.; Materials - G.K., E.Y.E.; Data collection and/ or processing - G.K., E.Y.E.; Data analysis and/or interpretation - E.Y.E., G.K.; Literature search - G.K., E.Y.E.; Writing - G.K.; Critical review - G.K., E.Y.E., H.B., M.A.

\section{References}

1. Klafke N, Eliott JA, Wittert GA, Olver IN. Prevalence and predictors of complementary and alternative medicine (CAM) use by men in Australian cancer outpatient services. Ann Oncol 2011;5:1-8.

2. Martin RK, Ian MH, Sabe SS, Beverley DG. Complementary and alternative medicine use in cancer: A systematic review. Complement Ther Clin Pract 2019;35:33-47.

3. Markus H, Gerd B, Gabriele D, Danuta L, Erik R, Marcel Z. How many cancer patients use complementary and alternative medicine: A systematic review and metaanalysis. Integr Cancer Ther 2012;11(3):187-203.

4. Korkmaz M, Tavsanli NG, Ozcelik H. Use of complementary and alternative medicine and quality of life of cancer patients: Turkish samples. Holist Nurs Pract 2016;30(2):88-95.

5. Zöhre I, Özgür T, Hilal Ö, Derya DU. Use of complementary and alternative medicine and quality of life of cancer patients who received chemotherapy in Turkey. Complement Ther Med 2019;44(4):143-50.

6. Algier LA, Hanoglu Z, Ozden G, Kara F. The use of complementary and alternative (non-conventional) medicine in cancer patients in Turkey. Eur J Oncol Nurs 2005;9(2):138-46.

7. Ayfer BC, Ayse CA, Sevgin SB. The use of complementary and alternative medicine among lymphoma and cancer patients with a solid tumor: Oncology clinics at Northern and Southern Turkey. Complement Ther Med 2019;47:102173.

8. Inanc N, Sahin H, Cicek B, Tasc1 S. Use of herbs or vitamin/mineral supplements by patients with cancer in Kayseri, Turkey. Cancer Nurs 2006;29(1):17-20.

9. Can G, Erol O, Aydiner A. Quality of life and complementary and alternative medicine use among cancer patients in Turkey. Eur J Oncol Nurs 2009;13(4):287-94.

10. Deng GE, Cassileth BR, Cohen L, Gubili J, Johnstone $\mathrm{PA}$, Kumar $\mathrm{N}$, et al. Integrative oncology practice guidelines. J Soc Integr Oncol 2007;5(2):65-84.

11. Ernst E, Armstrong NC. Lay books on complementary/alternative medicine: A risk factor for good health. Int J Risk Saf Med 1998;11:209-15.

12. Hubner J, Muenstedt K, Muecke R, Micke O, Stoll C, Kleeberg UR, et al. Counseling cancer patients on complementary and alternative medicine. Background, theory, and implementation of nationwide counseling facilities. Strahlenther Onkol 2013;189(8):613-7.

13. Maguire P. Managing psychological morbidity in cancer patients. Eur J Cancer 2000;36(5):556-8.

14. Linden W, Vodermaier A, MacKenzie R, Greig D. Anxiety and depression after cancer diagnosis: Prevalence rates by cancer type, gender, and age. J Affect Disord 2012;141(2-3):343-51. 
15. Molassiotis A, Panteli V, Patiraki E, Ozden G, Platin $\mathrm{N}$, Madsen E, et al. Complementary and alternative medicine use in lung cancer patients in eight European countries. Complement Ther Clin Pract 2006;12(1):34-9.

16. Gage H, Storey L, Mcdowell C, Maguire G, Williams P, Faithfull S, et al. Integrated care: Utilisation of complementary and alternative medicine within a conventional cancer treatment centre. Complement Ther Med 2009;17(2):84-91.

17. Rakovitch E, Pignol JP, Chartier C, Ezer M, Verma S, Dranitsaris $\mathrm{G}$, et al. Complementary and alternative medicine use is associated with an increased perception of breast cancer risk and death. Breast Cancer Res Treat 2005;90(2):139-48.

18. Hyodo I, Amano N, Eguchi K, Narabayashi M, Imanishi J, Hirai $M$, et al. Nationwide survey on complementary and alternative medicine in cancer patients in Japan. J Clin Oncol 2005;23(12):2645-54.

19. Zigmond AS, Snaith RP. The Hospital anxiety and depression scale. Acta Psychiatr Scand 1983;67(6):361-70.

20. Tatsumara Y, Maskarinec G, Shumay DM, Kakai H. Religious and spiritual resources, CAM, and conventional treatment in the lives of cancer patients. Altern Ther Health Med 2003;9(3):64-71.

21. Molassiotis A, Fernadez-Ortega P, Pud D, Ozden G, Scott JA, Panteli V, et al. Use of complementary and alternative medicine in cancer patients: A European Survey. Ann Oncol 2005;16(4):655-63.

22. Wanchai A, Armer JM, Stewart BR. Complementary and alternative medicine use among women with breast cancer: A systematic review. Clin J Oncol Nurs 2010;14(4):E45-55.

23. Kristoffersen AE, Fonnebo V, Northeim AJ. Do cancer patients with a poor prognosis use complementary and alternative medicine more often than others? J Altern Complement Med 2009;14:1115-20.

24. Adams KE, Cohen MH, Eisenberg D, Jonsen AR. Ethical considerations of complementary and alternative medical therapies in conventional medical settings. Ann Intern Med 2002;137(8):660-4.

25. Sparreboom A, Cox MC, Acharya MR, Figg WD. Herbal remedies in the United States: Potential adverse interactions with anticancer agents. J Clin Oncol 2004;22(12):2489-503.
26. Tascilar M, de Jong FA, Verweij J, Mathijssen RH. Complementary and alternative medicine during cancer treatment: Beyond innocence. Oncologist 2006;11(7):732-41.

27. Rockwell S, Liu Y, Higgins SA. Alteration of the effects of cancer therapy agents on breast cancer cells by the herbal medicine black cohosh. Breast Cancer Res Treat 2005;90(3):233-9.

28. Cao P, Selvan SR, Akkol EK, Wang N, Yang H, Cheng $\mathrm{X}$. Complementary and alternative medicine in cancer prevention and therapy. Evid Based Complement Alternat Med 2015;2015:639372.

29. Roberts CS, Baker F, Hann D, Runfola J, Witt C, McDonald J, et al. Patient-physician communication regarding use of complementary therapies during cancer treatment. J Psychosoc Oncol 2005;23(4):35-60.

30. American Cancer Society. Complementary and Alternative Methods and Cancer. Atlanta, Georgia, United States: American Cancer Society; 2020. Available from: http://www.cancer.org/treatment/treatmentsandsideeffects/complementaryandalternativemedicine/complementaryandalternativemethodsandcancer/index. Accessed Dec 06, 2020.

31. Lettner S, Kessel KA, Combs SE. Complementary and alternative medicine in radiation oncology: Survey of patients' attitudes. Strahlenther Onkol 2017;193(5):419-25.

32. Health Services General Directorate. DGCA Traditional, Complementary and Functional Medicine Practices Department. Available at: https://tcamanatolia.saglik.gov.tr. Accessed Dec 6, 2021.

33. Wetzel MS, Eisenberg DM, Kaptchuk TJ. Courses involving complementary and alternative medicine at US medical schools. JAMA 1998;280(9):784-7.

34. Wharton R, Lewith G. Complementary medicine and the general practitioner. BMJ 1986;292(6534):1498500 .

35. Burstein HJ, Gelber S, Guadagnoli E, Weeks JC. Use of alternative medicine by women with early-stage breast cancer. N Engl J Med 1999;340(22):1733-9.

36. Ganz PA, Desmond KA, Leedham B, Rowland JH, Meyerowitz BE, Belin TR. Quality of life in long-term, disease-free survivors of breast cancer: A follow-up study. J Natl Cancer Inst 2002;94(1):39-49. 